Moloi, T.J. \& Adegoriolu, E.T. The Transformative Methodology: Expository Study of Teaching English as the Second Language Acquisition

\title{
The Transformative Methodology: Expository Study of Teaching English as the Second Language Acquisition
}

\author{
Tshepang Jacob Moloi ${ }^{* 1}$ \& Emmanuel Tobi Adegoriolu ${ }^{1}$ \\ *Corresponding Author: moloijac@yahoo.com \\ 1. North-West University, Faculty of Education, South Africa. \\ Received : 2021-06-17 \\ Revised : 2021-08-21 \\ Accepted : 2021-09-15
}

\section{Abstract}

The significance of language as a science in the educational sector has continued to play a critical role in terms of teaching and learning. However, due to inequalities exposed severely by the Covid-19 pandemic, the teaching of English as the second language acquisition to foreign speakers; is adversely affected. Therefore, the use of transformative methodology as the teaching strategy is explored to determine the most suitable methodology of teaching during the Covid-19 pandemic. The study utilizes Participatory Action Research as the approach to explore the efficacy of transformative methodology; this approach is embedded in the paradigmatic principles of constructivism as the lens of qualitative methodology. Besides, the data is analysed using Critical Discourse Analysis post the generation of it using observations and semi-structured interviews (free attitudinal interviews). The paper demonstrates the prospects of using transformative methodology as the appropriate use of pedagogical strategy for English as the second language acquisition, it also suggests efficient but costly measures required to be implemented by the universities for the use of the transformative methodology.

Keywords: Second language acquisition; Covid-19; transformative methodology; teaching strategy and inequalities.

\section{Introduction}

The dynamics of the globe unconventionally evolved because of the Coronavirus (Covid-19) pandemic. Its emergency is quite distinctive from other pandemics or phenomena since the globe, by and large; was neither prepared nor anticipated that the equitable use of limited resources to be effective given its magnitude to combat and manage its effects. Notwithstanding this pandemic, South Africa, similarly to other countries, was not spared from the adverse impact of it. On the $11^{\text {th }}$ March 2020, World Health Organisation (WHO) declared Covid-19 as a pandemic and since then, the status quo in our societies and the world in general; deteriorated and the perpetual distribution of uneven resources abated. As a result, countries 
Moloi, T.J. \& Adegoriolu, E.T. The Transformative Methodology: Expository Study of Teaching English as the Second Language Acquisition

across the world had to contingently develop coping mechanisms and hence various measures of lockdown were implemented in an attempt to curb the spread of the Covid-19. Amid these challenges presented forth the pandemic, like other dimensions such as political, economic and labour; the educational sector was not immune from the voracious effects of the pandemic.

This implied that our limited resources suffered profound pressure and this perpetuated the high levels of inequalities among our students, instructors and high institutions of learning, as conceded by Aristovnik et al. (2020) that among other relative stakeholders within the education system, students are the main victims to be adversely affected by the pandemic. Factually, the pandemic shall remain with the globe for quite some time, hence the paper aims to expose the efficacies of using transformative method in the context of teaching English as the Second Language under Covid-19. The fundamental basis to expose efficacies of using transformative method is mainly to view the challenges of transformative method and its impact on teaching English as the second language.

\section{Research Question}

How effective is the use of transformative methodology to teach English as the Second Language at the university?

\section{Research Objectives}

The aim of the paper is to expose the efficacies of using transformative methodology to teach English as the second language at the university. While the objectives of it is to:

- Determine the challenges of using transformative methodology as the teaching strategy.

- Discover the efficacies of using transformative methodology as the teaching strategy for ESL at the university.

\section{Literature Review}

The emergency of Covid-19 seems to have an adverse impact on all universities although such an impact is not measurably drastic to other universities (Omodan, 2020). This means that students who emerged from impoverished backgrounds will feel the brunt of this pandemic, although students' determination for tertiary education is espoused by their personal goals and ambitions to better their diverse backgrounds. The fact that students emerged from diverse backgrounds consisting of abject poverty, inequality, crime and other social ills with the purpose of transforming their lives to eradicate the widening gap of inequality, cannot be delayed by this pandemic. Certainly, students' experiences as a result of Covid-19 have raised alarm concerning their potential to succeed in accomplishing their educational goals (Aristovnik et al., 2020; Tarman, 2020), and universities and colleges' state of finances have exponentially deteriorated and resulted in financial distress. This notion is purported by Abdullah and Haider (2020) when opined that enormous financial inadequacies have adversely impacted the institutional directions in terms of leadership and management. This indicates that pertinent expertise, skills relevant to the pandemic are required to mitigate the prevalent effects of the Covid-19 and to manage, efficiently; the use of the limited resources. Similarly, high institutions of learning are subjected to financial distress (Habibi et al., 2020) and this distress caused the instant shut down of some of the universities. The classical example is that of Alliave University 
Moloi, T.J. \& Adegoriolu, E.T. The Transformative Methodology: Expository Study of Teaching English as the Second Language Acquisition

College in Medical Sciences which closed shop as the results of the operational requirements (Husin et al., 2018).

Furthermore, these challenges exposed even the hidden elements of inequalities and resources and grant no further opportunities to salvage the remnants of the resources. This denotes that Covid-19 has no mercy when coming to the struggle of economic emancipation given the definition of it by Velavan and Meyer (2020) that Covid-19 is "positive-single stranded large RNA viruses which infect humans, but also different animals." Apart from animals, human beings are the core mechanisms in any dimension; hence human capital plays a pivotal role in economic activities. Kanu (2020) surmised the catastrophic effects of Covid-19 in threefold on economic activity, i.e. financial corporate, human mortality and job losses. This submission indicates that the significance of human capital surpasses; although not negating the significance of the other two dimensions, in essence, the value of the economy itself. It is because human capital in a narrow sense, inject not only expertise, skills and knowledge but contribute immensely towards police formation that enables the conducive environment for economic and political climates, which create profound opportunities for growth.

Therefore, it is prudent to infer that Covid-19 has widened the gaps of inequality and poverty because Zucman (2019) rebutted that Covid-19 has widened the gaps of inequalities since the distribution of wealth has subverted. This implies that wealth is not only limited to monetary value but includes, inter-alia; services, goods and resources. These services, good and resources serve as the bulk of capacity for effective functioning of high institutions of learning but because of the adverse impact of Covid-19, these institutions are compromised and obligated to adapt their traditional approaches of imparting skills and knowledge into the relevant and recent methods, thereof; transformative method (TM hereinafter) has been regarded as one of the best methods for teaching during this pandemic era (Beka \& Beka, 2017). As a result of this adaption, the TM can be used to teach English as the Second Language (ESL). It is because the state of readiness of the globe is subjected to rigour test to withstand the challenges of the pandemic (Beka, 2014). This implies that societies ought to evolve since we have digitalization and the $4^{\text {th }}$ Industrial Revolution (OECD, 2019), hence the subsequence use of the TM for teaching and learning ESL shall mitigate the compromise of the perks of the quality of teaching and learning.

Apart from the limitations of TM; it seems to be an alternative method for teaching and learning ESL as Beka and Gllareva (2016) endorsed that TM's outcomes are evident towards the contribution to a high quality of teaching and learning and this serves as the opportune lacunae for using TM for teaching and learning ESL. However, this high quality of outcomes alluded by Beka and Glarella (2016) is substantially controversially because quality, reliability, validity and standard can be compromised when assessment is administered remotely without effective monitoring (Gardner, 2012).

However, the suspense of this controversy; to demystify the use of TM to teach ESL, need to be applied, thus certainly; language constitute an integral part of our lives and necessitates that the teaching of ESL, as the world progress and evolve; be altered and adapted to suit the current era. Based on this assertion; the Second Language's (SL) definition is distinctive from that of the language as the former is defined as the intense, involved and systemic study of 
Moloi, T.J. \& Adegoriolu, E.T. The Transformative Methodology: Expository Study of Teaching English as the Second Language Acquisition

people learning a new language apart of their mother tongue (Hogue, 2017) while the latter is the expression of ideas, opinions, facts and emotions utilizing the systemic method involved in a language, such as signs and symbols (Hogue. 2017).

Above all, the functions of language among others are to communicate and interact and the emerging contexts for these functions are critically important as the social function from an academic function. Argumentatively, individuals interact using their mother tongues in a social context and this interaction is premised on the concept coined by Cummins $(1981,1991)$ called Basic Interpersonal Communication Skill (BICS). In contrast, Cummins further coined the concept called Cognitive Academic Language Proficiency (CALP) for academic purposes (Cummings, 1981, 1991).

Therefore, depending on the context prevailing; these concepts are intertwined for effective communication, writing and reading using ESL and enable the potency of second language acquisition using these concepts interchangeably (Lehman Welch, 2020). As a result, the pertinent question arises of how ESL can be acquired amid the prevalence of Covid-19? Rhetorically, TM; which is the method embedded into the context of social change that inspires and influence people's experiences can significantly enhance the teaching and learning of ESL. These experiences are conflated with the meanings of life and the exposition of using TM to teach ESL is relevant and constitutes the genesis of this paper. In concise, the paper exposes the use of TM under the complex situation of the Covid-19 pandemic for teaching ESL at the university.

\section{Theoretical Framework}

The paper aims to expose the efficacies of using TM to teach English as the second language. However, this aim cannot be attained without expanding; in essence; the significant pertinent question of what constitutes, by definition and usage; transformative method. Therefore, in narrow sense transformative method means the action that is involved on teaching process by way of substance and validation (Farren, 2019). In a broader sense, transformative method entails the activity of validating, reasoning, inquiring and reflecting on our perspectives during the cause of teaching (Craton \& Taylor, 2012). Based on these two definitions; the paper adopts the subsequent one since it exposes the efficacies of TM on teaching ESL and appreciates the fact that when the necessicity arises to embrace change, such should be done without hesitation. It is because TM is enshrined on the elements of values and morality where social interaction endorses the use of language (Farren, 2016; Shatunova et al., 2021).

As a result, this infers that students interact in a social context primarily to transform their values and morality to appropriate them for teaching and learning. Learning language is not predicable and conventional as the process tend to be complex and not linear (Menezes, 2013; Adams, 2020). So language is scientific in nature and requires set of techniques and approaches employed to bridge the gaps of second language acquisition. Therefore, the second language acquisition (SLA) is the theoretical genesis to expose the efficacies of using TM to teach it. Insofar as TM concerned, there is dialectical relationship between TM and SLA in the sense that TM does not only produce competent and skilled speakers but also extend their potency to contribute on the social cause of solving social phenomena and problems. Similarly, SLA is 
Moloi, T.J. \& Adegoriolu, E.T. The Transformative Methodology: Expository Study of Teaching English as the Second Language Acquisition

defined as the technique for communication purpose and interaction within the context of education, corporate or organisation among non-English speakers (Aljumah, 2020).

Conversely, SLA has the potency to affect our behaviour towards language acquisition hence its development from behaviourist point of view, descend into the perspective that learning any second language is induced by the stimulus and responses (Parker, 2019; Skinner, 1957) and these stimulus and responses augur well with the action of teaching which is espoused by TM. In brief, there is an action involved that need to be taken by both instructors and students and based on this requirement, SLA pose a challenge to English none speakers as English is dominantly used as the medium of instruction for various reasons, among other including but not limited to: economic, educational, business, political, technological and social reasons. Critical to emphasis that SLA's theories for language learning deem not adequately sufficient to hypothesis how SLA is learnt (Aljumah, 2020; Vu, 2019), thereof; exposing the use of TM as the theory for teaching SLA will add to the already existing other theories such as universal grammar (Chomsky, 1957) for expanding the options of instructors to utilize theories for teaching second language.

\section{Methodology}

The paper aims to expose the efficacies of using TM in the context of teaching ESL under Covid19. Therefore, it utilizes the constructivist paradigm as the lens to zoom into the qualitative data. The choice of this paradigm is premised on the rationale that people, as socialite and inquisitive by nature; utilize their experiences, skills and knowledge to learn, reflect and decipher from them (Dickson et al., 2016). It is because experiences and knowledge constitute the crux of the learning, hence constructivist believe that students should engage into an exercise of problem solving by the process to unlearn the existing information relearn the new way in a form of reorganisation of data cognitively (Yadav, 2021). This infers that such a process of unlearning and relearning unfolds, students' critical and independent thinking is enhanced and widen hence we regard experiences and knowledge of students profound for distilling the efficacies of using TM to teach ESL.

When students constructively engage on their existing knowledge and experiences to acquire the new information, they seek to appreciate the recognition of these tenets by embracing change from the traditional way of teaching into the modern one (Ajdini, 2021). Therefore, the appreciation of this recognition affords rather creates the new path for acquisition of knowledge, skills and experiences for students and thus, connect these tenets with quality of data. As a result, the paper exposes the efficacies of using TM to teach ESL at the university using participatory action research (PAR) as the research design. Whitman et al. (2010), contend that PAR is the collective, tuition, action and participation utilized to collect data that can be functional to the quest of social transformation, therefore, one of the reasons to combine both the PAR and constructivism is that both serve the interests, values and insights of the people who are affected by the same problem (Molise, 2021). These techniques are also entrenched on the principles of liberty, emancipation and freedom for participants to partake on social research to socially demystify the social phenomena and constructs which affect them on daily basis (Adebola et al,. 2020). Thus creating the equal opportunity for both participants and principal researcher to enjoy the rights, responsibilities and duties to solve social 
Moloi, T.J. \& Adegoriolu, E.T. The Transformative Methodology: Expository Study of Teaching English as the Second Language Acquisition

phenomena and constructs (Dube \& Hlalele, 2018). Similarly, this assertion is endorsed by Jack and Krahlc (2006) when they accede that PAR distinguishes itself from other methods as it expounds on the significance of involvement, engagement and mutual understanding. This exploration necessitates the attrition that students ought to be initiators and active agents of their learning. Now, to expose the efficacies of TM for teaching ESL; PAR demonstrates the similar features of TM in the sense that in the latter, the individuals' experiences are meaningful and taken into cognisant and in the former individuals are engaged and involved with mutual understanding (MacDonald, 2014).

Equally so, the notion that human beings are the core components of teaching and learning and the primary goal is to preserve their lives and prevent any harmful effect on them, serves as the substantive basis for equal involvement and participation. Since the objective is to determine the efficacies of using TM to teach ESL under Covid-19, the introduction of TM in our educational sector is crucial and has brought significant improvements (Tallvid, 2016). This introduction of TM is in the form of ICT (information and communications technology); and it mitigates the contagion effects of infection among students and lecturers (Petterson, 2018). This infers that online learning serves as the source of interaction and negate physical interaction. On these bases, the study utilized the qualitative method because it is the method that developed and employed under social context and human sciences (Creswel, 2014) and actually entrenches the notion that social context precisely establishes the nature and type of data to be studied, evaluated, analysed and synthesized.

Hence, Poggenpoel and Myburg (2005) explicitly asserted that the concept 'data' is fundamentally dominant in this method merely because the aim is to solicit comprehension instead of hypothesis. In contrast, the data used from the employing of TM conjures the salient comprehension to alleviate the challenges of teaching ESL under Covid-19. This demonstrates the crucial aspects of bringing on board people's experiences and meanings by way of engagement and involvement, hence TM afford the students such expanded opportunities to engage and involve their lecturers.

The study analyses data using Critical Discourse Analysis (CDA) which is the technique utilized to analyse the logical relationship between semiotics and other dimensions of social practices (Faircough, 2001). This technique analyses the texts and interactions that occurred in the past and present, hence its relevance is embedded in the rationale that it allows people to exercise their freedom, independence and courtesy. It is further stated by Van Dijk (1998) that CDA analyses the written and spoken texts to precisely depict the discursive sources of dominance, exploitation, biasness and power. As a result, this technique is logically relevant to demonstrate that TM is of value and its efficacies can enhance the acquisition of ESL and data is transcribed verbatim in order to develop and interpret themes. In brief, the method and technique utilized do qualify the substantive aim of exposing the efficacies of TM because of their similar features characterized by a sense of independence, involvement, engagement and emancipation.

The social practices and structures which compel the prevalence of political, social and historical oppression appearing in our traditional classrooms, can be dissected, evaluated and substituted by the use of TM (Bukhari \& Xiaoyang, 2013). The paper adopted purposive sampling, whereby the participants were sampled from the population of fifteen (15) Second 
Moloi, T.J. \& Adegoriolu, E.T. The Transformative Methodology: Expository Study of Teaching English as the Second Language Acquisition

Language Experts out of which eight (8) were purposively sampled and consists of five (5) female experts and three (3) male experts.

The experts are the cohort of 28-57 year of ages who were interviewed using semi-structured interview conducted virtually in order to comply with the preventative measures of Covid-19. The role of the principal researchers is to facilitate this processes to ascertain that participants are fairly, transparently and unbiased interviewed as well as dispatching written interview questions for those who were not able to attend the virtual interview. This virtual interview lasted not more than 30 minutes per participant, this was in the interests of time constraints these experts were working under.

The purposive sampling was chosen because it affords both the principal researcher and participants the equal opportunity to share their expertise and insights about this method; hence, the principles of engagement, involvement and active participation were accomplished. Suffice to mention that the participants were academic experts in teaching ESL and were asked and/or given the total form of fifteen (15) questions which ranged from open-ended questions to close-ended questions. To surmise, the collection of data transpired under the auspices of fairness, transparency, respect, intellectual emancipation, freedom and liberty and subsequently the accomplishments of the principles of the method and technique involved in this study in the quest to exposing the efficacies of TM for teaching ESL under the Covid-19 pandemic.

\section{Results}

The fact that the paper aims to expose the efficacies of using TM for teaching ESL; the results were quite interesting in the sense that participants were able to share insights and nuances which were not initially envisioned. Amid the first objective of the paper to determine the challenges which hinder the effectiveness of TM for teaching ESL, on average; participants indicated that TM poses number of challenges which ranged from the skills and expertise of utilizing the online management learning systems to the degree of inaccessibility by students to this online learning system. These challenges are transcribed verbatim in the following excerpt between the principal researcher and the participant, Mr. Mbewu as pseudonym.

Interviewer: Having more than ten (10) years of experience in higher education, have you ever thought that the sector will experience such an enormous transition from faceface to online learning?

Mr. Mbewu: Not in single moment of my thoughts did I think that we will have this online platform learning system, considering the fact that some of us are aging. This means that technological literacy is no more relevant.

Interviewer: How are you copying since the advent of this online system?

Mr. Mbewu: It is quite a struggle; my brother, we are learning along the implementation process as we have no choice but duty bound to teach even though we don't know how to teach online.

From the above excerpt, one denotes the sense of frustration from these experts as they are confronted with the conundrum of teaching under the difficult times of covid-19 and the 
Moloi, T.J. \& Adegoriolu, E.T. The Transformative Methodology: Expository Study of Teaching English as the Second Language Acquisition

insufficient prerequisite technological skills for online teaching and learning. In contrast, the young participants seem to be enthused into this online learning system as they indicated, in the following except; that online learning is costly but convenient, frank to use and expedient.

Interviewer: What are the challenges you have encountered using TM as the teaching strategy for ESL?

Ms. Lekae: For me it the water under the bridge, because since from high school to university; I experienced teaching and learning through online systems and so I found it vibrant and captivating for me to use it.

Interviewer: Is it because you have sufficient skills to use this system that makes it easy for you?

Ms. Lekae: Most definitely; having acquired technological skill from young age served as an advantage for me as I adapted quickly into the learning system. Although it is costly to implement it since you have to buy data or university make provision of this data to both students and lecturers.

Evidently, there are huge disparities in terms of the technological expertise and the age of personnel involved. These disparities infer the requirements of incessant training and development programmes for lecturers in order to remain relevant and abreast with the use of technology. However, the sense of ineptitude does not negate the factor of financial implications and lucidly demonstrated from the excerpt that, although young academics fare much better in terms of the use of technology compared to their counterparts; training and development programmes add the burden of costs incurred by universities in terms of skill empowerment.

In addition to the challenges of using TM as the strategy to teach ESL, it has been established that students tend to similarly experience attention deficit when they are in physical sittings. The following except indicate evidentially how this attention deficit hinder the efficacies of TM:

Interviewer: Do you find TM as more effective to use than face-to-face contact?

Ms. Ana: Not so much because one cannot detect the concentration and attention of students as some of them are might not be physically before their devices but just listening while doing something else. And this shows that they are clearly not paying full attention.

Interviewer: So how will you curb such deficiency to aid effective teaching and learning?

Ms. Ana: It is difficult but you will now and then pose pertinent questions to retain their attention, but it is not sufficient as some of the students will just respond on the chat box without articulating their responses.

This excerpt saliently indicates the challenges that couple the use of TM which can deter potential users of it. The most dominating issue here is the attention deficit although it is inevitable even from the physical contact, it seems to be difficult to control during the online learning. However, these challenges do not outweigh the effectiveness of TM for teaching ESL as it is demonstrated in the following excerpt: 
Moloi, T.J. \& Adegoriolu, E.T. The Transformative Methodology: Expository Study of Teaching English as the Second Language Acquisition

Interviewer: How will you describe the teaching and learning process on the use of TM?

Ms. Annette: I find it interesting in the sense that students are self-driven and have the sense of ownership for their learning. They now and then enquire as to when shall we have synchronous online teaching and learning which depicts their self-directed learning.

Interviewer: Is it fair to infer that TM has changed the landscape and trajectory of teaching and learning?

Ms. Annette: I want to believe that because now students have the zeal and inclination to login and learn unlike waking up early in the morning to prepare for an eight on the clock class. So in their comfort of their homes or residences, they just login and continue with learning.

The efficacies of using TM are explicitly demonstrated in these excepts as the students have developed the sense of ownership and being active agents of their learning. Primarily because students have ceased to commute from their residential areas to university campus in the quest of attending the morning and day classes. However, the limitations or challenges of TM are characterised by attention deficit, sufficient and affordable technological training programmes for lecturers, and the level of anxieties and frustrations presented forth by the use of technology for ole age lecturers. Albeit these challenges, there is a need for transition from traditional methods of teaching to the modern one, i.e. using TM to demonstrate the significance of it as the effective teaching strategy for ESL. These excepts formulate the classical example that educational sector is gradually transforming to remain afloat to be relevant and innovative.

\section{Discussion}

This paper aims to expose the efficacies of using TM to tech ESL under Covid-19 and in this section challenges and efficacies of using TM are elucidated on the basis of results in order to achieve the research question and objectives.

\section{Challenges of TM}

Firstly, it was established that the use of TM presented various challenges which hinder the effectiveness of teaching and learning, especially from the lecturers' point of view because the lecturers; who in this regard are considered as experts of teaching ESL, conceded that the online teaching presented the reasonable apprehension as some of them are not competently skilled to teach online using the gadgets or laptops. This finding is congruent with the insight hinted by Beka (2021) that online teaching brought the levels of anxieties and stress as $54,6 \%$ of teachers felt stress before the online lesson began. Similarly, the finding of this aspect concurs with this view of Beka (2021) that majority of participants indicated that they felt inadequately prepared and not ready to venture into online teaching. In addition, to exacerbate the matter; the participants stated that they felt that this online teaching subject them to tedious and rigour surveillance as whatever that they may disseminate, students will instantly verify the facts of it by using Google. 
Moloi, T.J. \& Adegoriolu, E.T. The Transformative Methodology: Expository Study of Teaching English as the Second Language Acquisition

Secondly, the study discovered that the respondents had reservations about attention deficit since the strategies and tactics of classroom management in the online sittings are obscure and difficult to implement. This implies that the retention of students' attention, on the online sitting of teaching and learning; is not effective since the diagnostic task of gauging their existing knowledge cannot be explicitly detected as some students can conceal their visibility online. Squarely, this response is endorsed by Barrot (2015) when stated that the baseline assessment to gauge the existing rather previous knowledge of students can be difficult to administer because its reliability and validity is not guaranteed. However, these challenges do not negate that TM does not provide alternative means of learning since students find it convenient as they do not have to wake up early in the mornings in preparations for the class

\section{Efficacies of using TM to teach ESL at the university}

Previously, reservations in terms of challenges are discussed on the basis of data generated. However, these reservations do not supersede the efficacies of using TM as the participants indicated that the perks of using online teaching as the TM, has afforded them additional opportunities for their students to experience teaching and learning in an individualized manner. This individualized manner is cited as the means of acquiring additional information from other sources apart from that imparted to them by lecturers. Furthermore, participants indicated that students are the active agents of their learning because invariably they hint at the schedule of the online class in order to address the misunderstanding encountered during their learning remotely. Concerning being active agents, the students felt to experience collaborative learning much better than when they are in the physical setting. It is because a handful of students are timid to express themselves before their fellow peers and lecturers, however; they felt at ease expressing themselves online because they can conceal or hide their faces.

Consequently, responses further indicate that although students' might have attention deficit, they have the zeal to learn, hence, after the online teaching; they would go back to the lesson for reflection purposes and this process is evident by the lecturers' being inundated with emails of follow-up questions to demonstrate self-directed learning. Therefore, if students can reflect on the lessons; this implies that they can internalize their learning which subsequently cement the process of acquisition of knowledge. It is because the more they get exposed to the content and/or subject matter, the more they become learned. This assertion is expounded by Berner, Lobo and Silva (2013) that when students conduct the reflection on the lesson, they merely implement the acquired skills and knowledge into the contexts of their real-life situations. On top of this, when the implementation of skills into a real-life situation is conducted, internal learning occurs and as such, long-lasting and decisive decisions are established as the results of this process. In brief, this is the salient demonstration that TM for teaching ESL under covid-19 would further entrench the exercise of reflection.

Furthermore, the participants extrapolated that TM creates an expanded opportunity for students to own their learning. Once students have ownership for teaching and learning, they understand their role and ultimately manage to accomplish their educational goals. Patently, lecturers' roles are mainly that of facilitating the process of teaching and learning and such, the students' ownership is depicted by the degree of responsibilities that come with their learning. 
Moloi, T.J. \& Adegoriolu, E.T. The Transformative Methodology: Expository Study of Teaching English as the Second Language Acquisition

Students have to ascertain that they have sufficient data before online learning can commence, moreover, students have to make sure that learning materials are procured timely and time is adequately managed in terms of executing assessments and meeting all the deadlines for submissions. All these factors encompass the trait of responsible students who understand the purpose of teaching and learning by not lightly taking these online classes for granted. Comparatively, a traditional method of teaching whereby attention is accentuated to compulsory; was never considered to be a matter of success and failure, but since the TM has been implemented in the context of teaching and learning, students have begun to reconcile and critically understood the significance of attending these online classes.

Finally, the study established that through TM; students were able to query their perspective, views, and conceptualizations by constructing new phenomena, paradigms and facts in a manner that diffused their preconceived ideas and existing knowledge. This infers that additional learning opportunities to scaffold students were less employed by lecturers as now students were able to critically synthesize and evaluate what they learned. Therefore, the sustained challenges are discovered and addressed by students as it is succinctly indicated by Berner et al. (2013) that the prevalence and emergency of challenges make the TM work effectively, as a result; TM can withstand diverse challenges because it has the potency to impact positively the process of teaching and learning.

In concise, the general findings between the challenges and effects TM demonstrated that if TM is properly utilized, it can yield vibrant and tangible results as it encourages individual or self-directed, ownership and collaborative learning, reflection and paradigm shifts of students. Equally, the findings further propel the notion that sustainable challenges which are of a relevant feature of skills and knowledge required can inspire and learn as students can critically evaluate, synthesize and deduce meaning which, the latter is of the most imperative tenet of intellectual emancipation.

\section{Conclusion}

The paper establishes and exposes the challenges and efficacies of using TM to teach ESL under the covid-19 pandemic by generally indicating how important to have interactive teaching and learning process, and its aim is achieved using the principles of PAR and constructivism which emphasis collaboration in research and learning using our own experiences. In contrast, the paper pinned down the perpetual revelation of inequalities since the challenges of procuring data, laptops or gadgets constitutes the financial aspect which can be a dire challenge to the majority of students. Hence, further studies are required to focus on how the provisions of these resources can be made exponentially and readily available to enable the use of TM under the conditions of the covid-19 pandemic.

Furthermore, the study established that the TM can be used one of the teaching strategy to tech any second language for non-speakers. The results demonstrated that using TM as the online source of teaching, aid the students to acquire ownership or self-directed learning in a sense of initiating their learning, being active agents of their learning and achieving collaborative learning. It is therefore, our view that TM qualifies as one of the learning theories of SLA despite the challenges presented by it which necessitate the emergency of further studies to search the mitigating measures of these challenges. Amid these challenges, the study 
Moloi, T.J. \& Adegoriolu, E.T. The Transformative Methodology: Expository Study of Teaching English as the Second Language Acquisition

did not evaluate by and large; how the challenges can be mitigated or averted. Therefore, further studies are required to focus on the mitigations of challenges of using TM to teach ESL under covid-19.

Conversely, the paper exposed the efficacies of using TM as the strategy to teach ESL at the university. These efficacies include the action of students taking responsibility for their learning as they develop self-directed learning, tend to have ownership and collaborate for learning, it further indicated that the use of their existing knowledge or experiences trigger interest and curiosity; which in turn affirm the premise of constructivism that people use their existing knowledge and experience to interpret and improve on the new one. This is the prerequisite for second language acquisition as conceptual development is embedded on the interest to learn using, firstly; the mother-tongue before transition to second language (Chomsy, 1957). Therefore, the effectiveness of using TM as the teaching strategy to teach ESL at the university, are evidently characterised by the use of this recognisable teaching strategy to develop academic language proficiency and social communication skill.

\section{References}

Abdullah, M \& Haider, A. (2020). Development of Post-Pandemic Covid19 Higher Education Resilience Framework in Malaysia. Archives of Business Research, 8(5), 201-210.

Adams, B. (2020). How English-Speaking Teachers Can Create a Welcoming Environment that Allows Students to Maintain and Utilize their Language through Translanguaging: A Qualitative Case Study. Journal of Culture and Values in Education, 3(2), 196-211. https://doi.org/10.46303/jcve.2020.20

Adebola, O.O., Tsotetsi, C.T. \& Omodan, B.I. (2020). Enhancing Students' Academic Performance in University System: The Perspective of Supplemental Instruction. International Journal of Learning, Teaching, and Educational Research, 19(5), 217- 230. https://doi.org/10.26803/ijlter.19.5.13.

Aljumah, F.H. (2020) Second Language Acquisition: A Framework and Historical Background on Its Research. English Language Teaching, 13(8), 200-207.

Aristovnik, A, Kerzic, D, Rause, D, Timazevic, N \& Umek, L. (2020). Impact of Covid-19 pandemic on the life of higher education students: A global perspective. Sustainability, 12(20), 8438. http://dx.doi.org/10.3390/su12208438

Barrot, J. (2015). A Sociocognitive-Transformative Approach to Teaching Writing. Indonesian Journal of Applied Linguistics, 4(2), 132-122.

Beka, A. (2021). Transformative School Initiative throught the use of Digital Technologies in Kosovo during Covid-19. Ilkogretim Online - Elementary Education Online, 20(1), 851860.

Beka, A. (2014). Social networks as significant factor in the professional development of young people in Kosovo. Perspectives of Innovations, Economics and Business, 14 (3),147-151. https://www.ceeol.com/search/article-detail?id=440944

Beka, A. \& Gllareva, P. (2016) The importance of using electronic portfolios in teachers work. Applied Technologies and Innovations, 12(1), 32-42. 
Moloi, T.J. \& Adegoriolu, E.T. The Transformative Methodology: Expository Study of Teaching English as the Second Language Acquisition

Beka, B \& Beka, A. (2017). The lack of Electronic Thesis and Dissertations (ETD) database and its impact to doing research in Kosovo's Universities. DisCo 2017 Open Education as a way to knowledge society (pp.410-419). Prague: Center for Higher Education Studies.

Berner, S, Lobo, N \& Silva, N. (2013). A Strategic and Transformative Approach to Education for Sustainable Development. Master's Degree Thesis, School of Engineering Blekinge Institute of Technology Karlskrona, Sweden.

Bukhari, N. H \& Xiaoyang, W. (2013). Critical Discourse Analysis and Educational Research. Research and Methods in Education, 3(1), 9-17.

Chomsky, N. (1957). Syntactic structures. De Gruyter Mouton.

Cranton, P., \& Taylor, E. W. (2012). Transformative learning theory: Seeking a more unified theory. In E.W. Taylor \& P. Cranton (Eds.), The handbook of transformative learning: Theory, research, and practice. Jossey-Bass.

Creswel, J.W. (2014). Qualitative, Quantitative and Mixed Method. Sage Publication

Dube, B. \& Hlalele, D. (2018). Engaging critical emancipatory research as an alternative to mitigate school violence in South Africa. Educational Research for Social Change, 7(2), 74-86.

Faircough, N. (2006). Language and Globalization. Routledge.

Farren, P. (2019). Transformative Pedagogy' in Language Teacher Education. Books on Demand.

Gardner, J. (2012). Assessment and Learning: Quality Assessment Practice. (2 ${ }^{\text {nd }}$ ed.). Sage.

Habibi, A., Razak, R. A., Yusop, F.,D., Mukminin , A., \& Yaqin, L. N. (2020). Factors affecting ICT integration during teaching practice: A multiple case study of three Indonesian Universities. The Qualitative Report, 25(5), 1127-1144.

Husin, A., Abdullah, H., \& Ali., J. (2018). Harnessing Business Continuity Management in Malaysian Universities. Public Health Research and Development, 9(12), 2593.

Jack, J. \& Krahlc, R. (2006). Scaffolding and Achievement in Problem-Based and Inquiry Learning: A Response to Kirschner, Sweller, and Craig. Educational Psychologist, 42(2), 99-107.

Kanu, I.A. (2020). Covid-19 and Economy: An African Perspective. Journal of African Studies and Sustainable Development. 3(2), 2630-7073.

Lehman, C., \& Welch, B. (2020). A Quantitative Investigation of Language Policy in International Schools in East Asia. Research in Educational Policy and Management, 2(2), 1-18. https://doi.org/10.46303/repam.2020.1

MacDonald, C. (2014). Understanding Participatory Action Research: Qualitative Research Methodology Option. Canadian Journal of Action Research, 12(2): 34-50.

Molise, H. (2021). Pathways to Mitigate Challenges of Learner Academic Performance in a Grade 10 Economics Class in South Africa. Research in Social Sciences and Technology. 6(1), 83-101.

OECD, (2019). OECD Skills Outlook 2019: Thriving in a Digital World. Paris: OECD Publishings. http://hdl.voced.edu.au/10707/505508.

Omodan, B. I. (2020). The Vindication of Decoloniality and the Reality of COVID-19 as an Emergency of Unknown in Rural Universities, International Journal of Sociology of Education, Special Issue: COVID-19 Crisis and Socioeducative Inequalities and Strategies to Overcome them, 1-26. http://doi.org/10.17583/rise.2020.5495 
Moloi, T.J. \& Adegoriolu, E.T. The Transformative Methodology: Expository Study of Teaching English as the Second Language Acquisition

Parker, J. (2019). Second language learning and cultural identity. Journal of Curriculum Studies Research, 1(1), 33-42. https://doi.org/10.46303/jcsr.01.01.3

Petterson, F. (2018). On the issues of digital competence in educational contexts - a review of literature. Education and Information Technologies. 23, 1005-1021.

Poggenpoel, M \& Myburg, C. (2005). Qualitative research strategies as prerequisite for quantitative strategies. Acta Academica: 43(4), 153-158.

Shatunova, O., Bozhkova, G., Tarman,B. \& Shastina E. (2021). Transforming the Reading Preferences of Today's Youth in the Digital Age: Intercultural Dialog, Journal of Ethnic and Cultural Studies, 8(3), 62-73. DOI: http://dx.doi.org/10.29333/ejecs/347

Tallvid, M. (2016). Understanding teachers' reluctance to the pedagogical use of ICT in the $1: 1$ classroom. Education and Information Technologies, 21, 503-519.

Tarman, B. (2020). Editorial: Reflecting in the shade of pandemic. Research in Social Sciences and Technology, 5(2), i-iv. https://doi.org/10.46303/ressat.05.02.ed

Van Dijk, T. A. (1998). Critical discourse analysis. Available at http://www.carleton.ca/jsheyhol/cda.htm

Velavan, T.P \& Meyer, C.G. (2020). The Covid-199 Pandemic. Tropical Medicine and International Health. 25 (3) 278-280.

Vu, T. (2019). Theoretical Constructs and Practical Strategies for Intercultural Communication. Journal of Curriculum Studies Research, 1(1), 43-53. https://doi.org/10.46303/jcsr.01.01.4

Whitman, G \& Milledge, D. (2010). Participatory Action Research Toolkit: An introduction to using PAR as an Approach to Learning, Action and Approach. Durham University \& Lune Rivers Trust.

Williams, T.K., McIntosh, R.W., \& Russell, W.B. (2021). Equity in Distance Education During COVID-19. Research in Social Sciences and Technology. 6 (1), 1-24.

Zucman, G. (2019). Global Wealth Inequality, Annual Review of Economics, 11, 109-138. 